\title{
EDITORIAL: ENSINO E PRÁTICA DA TRADUÇÃO: O PAPEL DAS NOVAS TECNOLOGIAS
}

Carolina Barcellos

Universidade de Brasília

cpbarcellos@gmail.com

Os últimos anos viram um aumento exponencial na quantidade de ferramentas e softwares auxiliares à tradução disponíveis no mercado. Essas ferramentas são produzidas tanto pelo setor privado quanto por grupos de pesquisa dentro das universidades públicas, podendo ainda estar direcionadas à prática ou ao ensino da tradução. E, embora seja verdade que o interesse em comunicar-se com outras culturais não é novo, a velocidade com que isso é feito se tornou um fator decisivo. O mundo globalizado pela internet e a sofisticação tecnológica do século XXI permitiram que a tradução automática passasse a utilizar redes neurais para "ensinar" máquinas a traduzir cada vez melhor. Isso está, hoje, na base de uma nova geração de ferramentas e softwares para a tradução em seus mais variados contextos.

A localização, por exemplo, se aprimorou a ponto de criar uma fase intermediária chamada internacionalização, etapa em que é desenvolvida uma versão "genérica" de um produto de forma que se possa adaptá-lo facilmente a diferentes línguas e culturas ao mesmo tempo. O trabalho de dubladores e legendistas se ampliou para incluir a acessibilidade, tornando tanto a audiodescrição como a legendagem para surdos possíveis. A propagação veloz de informações on-line reacendeu discussões sobre qualidade e ética na tradução, gerando ferramentas capazes de identificar plágio. A tradução de best-sellers e manuais industriais em pouquíssimo tempo multiplicou o uso de memórias de tradução. As pesquisas concentradas no trabalho dos intérpretes e no processo tradutório, por sua vez, se beneficiaram de uma gama diversa de ferramentas associando-se com a medicina e a psicologia para obterem resultados mais precisos. A identificação de padrões de escolha e hábitos linguísticos passou a contar com programas de base estatística para a análise de quantidades de dados na ordem de bilhões de palavras.

Para a tradução, muitas são as oportunidades e muitos também são os obstáculos. O acesso a tecnologias sofisticadas e recém-lançadas têm um custo nem sempre acessível aos departamentos de ensino da tradução no Brasil. Há impasses específicos entre o meio acadêmico e o mercado como, por exemplo, questões de direitos autorais envolvendo livros, programas e jogos que precisam ser debatidos. É verdade que há muitos esforços sendo feitos no desenvolvimento de softwares livres e ferramentas gratuitas, normalmente disponibilizadas on-line. Para ampliar esse debate, esta revista busca lançar luz em questões específicas da interface entre tradução e tecnologia.

A primeira seção desta revista chama-se Linguística e Tecnologia. O primeiro trabalho apresentado nessa seção é O uso da Lista de Consistência Detalhada (Detailed Consistency List) do WordSmith Tools@ 6.0 para investigação do perfil estilístico de quatro tradutores de Heart of Darkness para o espanhol, de Mayelli Caldas Castro. Nessa pesquisa, a autora mostra como dados quantitativos gerados a partir de um corpus paralelo podem identificar padrões linguísticos e indicar caminhos metodológicos mais 
adequados. Em Chope dos Mortos - a tradução de jogos de palavras em um estudo direcionado pelo corpus, Nilson Roberto Barros da Silva se vale da abordagem teóricometodológica da Linguística de Corpus para identificar jogos de palavras e discutir estratégias de tradução no par linguístico português-inglês. Encerrando essa seção, em Uma proposta de objeto de aprendizagem para futuros tradutores: a modalização em resumos científicos em português, espanhol e francês, as autoras Sandra Dias Loguercio, Mauren Thiemy Ito Cereser e Cleci Regina Bevilacqua voltam sua atenção à linguagem empregada em resumos científicos analisando o uso de modalizadores, com o auxílio de corpora comparáveis.

A segunda seção desta revista é Semiótica e Tecnologia. O primeiro trabalho dessa seção é Legendagem: uma atividade na aula de japonês, de Kyoko Sekino e Sueleni Vitória Rodrigues Takahashi. As autoras descrevem um exercício de ensino de legendagem no par linguístico japonês-português de cinco etapas, tomando como base teórica a Teoria da Relevância. Em Multimodality and evaluation of machine translation: a proposal for investigating intersemiotic mismatches generated by the use of machine translation in multimodal documents, Thiago Blanch Pires considera o aparato teóricometodológico dos estudos de multimodalidade a fim de analisar relações semânticas entre texto e imagem resultantes de traduções automáticas.

A terceira seção da revista é Ensino Superior e Tecnologia. O primeiro trabalho dessa seção, Teaching video game translation: first steps, systems and hands-on experience, das autoras Marileide Dias Esqueda e Érika Nogueira de Andrade Stupiello, contribui com a formação de tradutores para a localização de jogos em nível de graduação. Em Investigando adjetivos atributivos em traduções publicadas, em um sistema de tradução automática e na pós-edição monolíngue: contribuições para a pedagogia da tradução, Norma Fonseca analisa a tradução de adjetivos atributivos em três etapas, sendo a última uma atividade com estudantes de uma disciplina de prática de tradução.

A quarta seção, intitulada Entrevistas, são apresentadas entrevistas com dois profissionais que trabalham em subáreas bem distintas da tradução. A primeira entrevista, realizada por Janailton Mick Vitor da Silva e Alessandra Ramos de Oliveira Harden com a legendista Melina Agresta, traz contribuições sobre o mercado de legendagem no Brasil e a experiência de Melina com clientes como Netflix e HBO. A segunda entrevista, realizada por mim, coloca em foco o premiado tradutor Rogério Bettoni. O tradutor compartilha, nessa entrevista, sua vasta experiência com as principais editoras brasileiras e fala também sobre recursos eletrônicos disponíveis para os tradutores literários.

A última seção traz a tradução de um artigo publicado originalmente em inglês, no ano passado, pelos professores Stephen Crabbe (Universidade de Portsmouth, Reino Unido) e David Heath (Universidade de Kanto Gakuin, Japão) por meio da plataforma online do International Journal of English Language \& Translation Studies, de acesso livre. O artigo, Elaboração de um glossário de tradução utilizando software livre: um estudo de viabilidade a partir de textos-fonte em japonês, explora as possibilidades da extração automática de terminologia para a tradução mesmo ao se trabalhar com idiomas de famílias (e formas de escrita) essencialmente diferentes.

Essa edição da Revista Texto Livre foi especialmente preparada para dar destaque à interface entre tradução e tecnologia e, nesse sentido, fornece um panorama variado dos trabalhos atualmente produzidos no nosso país. Sem dúvida, esse conjunto de trabalhos é uma contribuição à disseminação de conhecimento e um incentivo a novos (e 
necessários!) pesquisadores interessados em testar os limites dessa interface. 